\title{
El absurdo quijotesco en Madame Bovary y El proceso.
}

\section{The quixotic absurd in Madame Bovary and The Trial.}

DOI: $10.32870 /$ sincronia.axxv.n80.12b21

\author{
Emmanuel Alejandro Godínez Romo \\ Centro Universitario del Sur. Universidad de Guadalajara (MÉXICO)
}

CE: emmanuel 1396@hotmail.com

Esta obra está bajo una Licencia Creative Commons Atribución-NoComercial 4.0 Internacional

Recibido: $26 / 08 / 2020$

Revisado: 06/05/2021

Aprobado: 18/06/2021

\section{RESUMEN}

Cuando Cervantes escribía el Quijote quizá no esperaba el alcance que tendrían las aventuras de su caballero andante. En el presente artículo, se pretende rastrear la influencia cervantina a través de la estructura y los personajes en dos de las obras más importantes de los siglos XIX y XX: Madame Bovary de Gustave Flaubert y El proceso de Franz Kafka. Es posible establecer una conexión entre estos autores con Cervantes gracias a que Flaubert y Kafka muestran o confesaron haber leído El ingenioso hidalgo don Quijote de la Mancha.

Palabras claves: Absurdo. Personaje. Sinsentido. Quijotesco. Flaubert. Kafka.

\section{ABSTRACT}

When Cervantes was writing the Quijote perhaps he did not expect the scope that the adventures of the knight errant would have. In this article is pretended to track the Cervantine influence trough the structure and the characters in two of the most important works in the nineteenth and twentieth centuries: Madame Bovary by Gustave Flaubert and The Trial by Franz Kafka. It is possible to establish a link between these authors with Cervantes thanks to Flaubert and Kafka show or confessed they read Don Quixote.

Keywords: Absurd. Character. Nonsense. Quixotic. Flaubert. Kafka. 
Entre las grandes novelas que se han escrito en los siglos XIX y XX indudablemente se deben mencionar Madame Bovary de Gustave Flaubert y El proceso de Franz Kafka. Ambas sumamente importantes para la literatura ya sea por lo insólito de sus situaciones o por lo entrañable de sus personajes. Estas obras no pertenecen solamente al país de origen de sus autores, ya que su trascendencia va más allá. Lo que está plasmado en los libros sobre Joseph K. y Emma Bovary no sólo se limita a la nación checa o francesa, sino que pertenecen al acervo de la literatura mundial. Sin embargo, Flaubert y Kafka produjeron sus textos gracias a la influencia cervantina. La mancha de don Quijote se oculta en las sombras de las aventuras - o desventuras-por las que se embarcan Joseph y Emma. En esta tríada de personajes, en momentos, es posible percatarse de lo absurdo de ciertas escenas. Entiéndase la palabra "absurdo" no como algo negativo, sino en el sentido de que las acciones de los personajes, en algunos momentos de las obras, se alejan de lo coherente o lo lógico, debido a las circunstancias por las que atraviesan. Para profundizar en las ideas anteriores, se empleará la semiología de los personajes, la concepción del concepto del absurdo, propuesto por Gilles Delueze y algunas de las ideas sobre el tiempo y los personajes de Roland Borneuf y Réal Ouellet para identificar el vínculo que une a don Quijote de la Mancha con los personajes de Madame Bovary y El proceso.

Si se ve a la literatura como un ente, casi como una deidad, es posible afirmar que obra de maneras misteriosas. Desde la primera publicación de El ingenioso hidalgo don Quijote de la Mancha en 1615 en España, el impacto que tuvo trascendió las fronteras hasta ser una novela conocida y primordial para los escritores fuera de las fronteras españolas. Por eso, al ser la primera novela moderna, no resulta extraño encontrar huellas del Caballero de la Triste Figura en ambientes y tiempos tan distintos, como en las provincias de Francia o el mundo banquero de lo que ahora es República Checa. El Quijote se volvió un espíritu capaz de poseer a otros personajes para insuflarlos con su locura para que cometan hazañas absurdas, en el caso de Emma Bovary. O de extender sus brazos como lanzas para atravesar a los miembros de un jurado y afectar con su falta de cordura al presunto delincuente Joseph K. En este último caso, se considera que su poder de posesión es tan 
enorme que afecta a una ciudad entera, sus calles y las personas que transitan por ellas (se profundizará en esta idea más adelante). Por otro lado, Emma se vio infectada por el mismo mal que aquejó a Alonso Quijano, generado por la lectura insaciable de libros. Estos rasgos o ambientes inverosímiles son posibles de rastrear hasta llegar inexorablemente a Miguel de Cervantes.

El personaje de don Quijote es imposible de analizar en unas cuantas páginas. Es una mina inagotable que cambia conforme a la época. Como ya se mencionó, el método que se empleará es la semiología de los personajes, la cual analiza a los actantes de las obras literarias a través de sus acciones, características físicas o incluso por el ambiente que los rodea. Los personajes han evolucionado al igual que la literatura, desde el héroe clásico que aparece en las épicas grecorromanas, como Aquiles, un ser con descendencia divina que se acerca peligrosamente a la perfección ${ }^{1}$. A partir de entonces, ha habido una degradación de los personajes, como la inclusión de más defectos o errores para acercarlos lo más posible a la realidad. Y, para su creación, los escritores pueden recurrir a su imaginación o tener una base obtenida de la realidad; se puede hablar de una relación intertextual de los personajes, ya que ellos "se influyen recíprocamente y se dan a conocer unos gracias a otros, tanto si se trata de grupos considerables como los mineros en huelga de Germinal o de figuras episódicas como la robusta chica de la jarra de leche de A l'ombre des jeunes filles en fleurs" (Borneuf \& Ouellet, 1989, p. 172). Don Quijote es una especie única en su tipo, ya que se aleja de cualquier clasificación y coquetea con lo extraño. Alonso Quijano es un caballero andante y no lo es, ya que su caminar por el mundo y las aventuras en las que se ve involucrado van de lo heroico-en extrañas ocasiones-a lo increíblemente patético. Su integración en un mundo que ya ha olvidado el paso de los caballeros está a destiempo. No obstante, la realidad que él quiere imponer está en constante conflicto con el mundo que lo rodea, un hecho

\footnotetext{
${ }^{1}$ Esta intención de los autores se debe a una necesidad de mostrar a sus personajes más humanos. En lugar de basarlos en los héroes mitológicos o semidioses, los principales cimientos se encuentran en las personas comunes y corrientes, los nobles, los burgueses, la gente del campo o los obreros. Dicho de otra forma, "Los sujetos en general se construyeron y se consideraron copia de personas: en forma directa (realismo), de forma abstracta, simbólica o alegórica (representación de virtudes o vicios generales), de acciones, de sentimientos, de valores morales, etc; algunos textos las trasladaron a animales, a vegetales, a seres inertes, investidos de cualidades, actitudes y palabra humana, de acuerdo con la idea de persona, de libertad, de conocimiento, prevalente en cada cultura" (Boves, 2018, p. 15).
} 
que aparenta ser apabullante y que parece poner en una enorme desventaja al Caballero de la Triste Figura.

Las posibles hazañas que se le presentan dependen primordialmente de la participación de los personajes secundarios que interactúan con el Quijote. Aquellos que aceptan que su posada es un castillo dispuesto a resguardar a los caballeros andantes o si las damas de compañía aceptan ser momentáneamente princesas. Si aceptan el juego, pretenden que el mundo de antaño que tanto anhela el caballero andante regrese para romper el tiempo e instalarse, por unos instantes, en el presente que viven. De no ser así, la realidad propuesta por el protagonista de la obra de Cervantes será completamente rechazada y entrará en el terreno de lo absurdo. Es decir, las acciones carecerán de lógica simplemente porque el oficio de los caballeros andantes es obsoleto. Un momento que es crucial para el desarrollo de la novela es el primer choque de realidades que presencia Sancho, en el capítulo de los molinos de viento:

-Mire vuestra merced-respondió Sancho- que aquellos que aquí se aparecen no son gigantes, sino molinos de viento, y lo que en ellos parecen brazos son las aspas, que, volteadas del viento, hacen andar las piedras del molino.

-Bien parece-respondió don Quijote- que no estás cursado en esto de las aventuras: ellos son gigantes; y si tienes miedo, quítate de ahí, y ponte en oración en el espacio que yo voy a entrar con ellos en fiera y desigual batalla (Cervantes, 2005, p. 66).

El resultado ya se conoce: la primera visión que se tenía de los gigantes es abruptamente desplazada por la de los molinos. El modo de actuar del Quijote se repetirá en sucesos posteriores, ya que, al ver que los gigantes han cambiado de forma, decide culpar a un hechicero enemigo suyo que le impidió llevar a cabo su hazaña.

\section{El Quijote viaja a Yonville}

Es hora de adentrarse en Madame Bovary para hablar sobre lo absurdo. Se mencionó que las hazañas quijotescas caminan por una cuerda floja en la que se balancean los pesos de lo heroico y 
lo disparatado; y para que se presente, es necesaria la intervención de que varios personajes participen, esto se debe a que "El absurdo nos señala una falta de coherencia y de correspondencia, va en contra de la razón y la manera en que ésta percibe la realidad" (Pérez, 2016, p. 867). Esto ocurre también en la novela de Kafka que se analizará más adelante. Aunque el caso que más se asemeja con el Quijote es Emma Bovary². El mundo idealizado que ella propone tiene más posibilidades de éxito, debido a que la realidad que ella busca es atemporal. Forma parte de un imaginario colectivo, de un deseo que han anhelado tanto hombres, como mujeres de todas las épocas de la historia. Su realidad, además, responde una necesidad común a cualquier sociedad en el mundo.

Emma Bovary comparte una semejanza que sólo puede ser considerada como quijotesca. Ella proviene de una vida en el campo y sueña constantemente con pasar sus días en la ciudad. Estos sueños que ella tiene comenzaron a emerger a partir de su lectura de novelas, en las que el romance y los amantes son vistos como una parte esencial de la vida parisina ${ }^{3}$. Piensa que sus deseos están a punto de hacerse realidad con la aparición del doctor Charles Bovary, quien contrae matrimonio con ella. El pasatiempo de Emma con las novelas es indispensable para la construcción de este personaje:

Había leído Pablo y Virginia y había soñado con la choza de bambú, el negro Domingo, el perro fiel, pero sobre todo con la amistad dulce de algún buen hermanito que va a buscar frutas rojas de árboles grandes, más altos que campanarios, o que corre descalzo por la arena para traerle un nido de pájaros. (Flaubert, 1989, p. 29).

\footnotetext{
${ }^{2}$ Esta no es la única relación entre los dos personajes. De igual manera, Flaubert escribió varias cartas, que expresan su admiración por la obra cervantina. “Carta a Louise Colet, noviembre de 1847: 'En estos momentos estoy releyendo Don Quijote en la nueva traducción de Damas-Hinard. Estoy impresionado con él, estoy obsesionado con España. iQué libro, qué libro! Cómo esta poesía es tan alegremente melancólica'" (Flaubert, traducido por Lilia Madrigal Ambriz, 2018, p. 58).

${ }^{3}$ Sin duda, otro de los aciertos de Flaubert en su novela es el uso del estilo indirecto libre. Un antecedente de lo que derivaría más tarde en el stream of conciusness que perfeccionaron autores, como Proust y Joyce. Lo que hace valiosa de igual manera tanto a Flaubert, como a Kafka y a Cervantes es que ellos, como novelistas comunican "sobre todo -a veces exclusivamente-, lo que sus personajes perciben del mundo en el que se mueven, siendo la novela el marco en el que se inscribe esa percepción, en la que los actos, proyectos y pasado de los personajes cuentan menos que las pulsiones, imágenes e impresiones que constituyen cada instante de sus vidas" (Borneuf \& Ouellet, 1989, p. 232).
} 
Los mundos ficticios que han entrado en la cabeza de Emma se han acumulado tanto que ya agotaron todo el espacio que podían ocupar. Buscará que su imagen idealizada que ella tiene de la realidad se traspase a su vida actual. Aquí es posible ver una similitud muy cercana con don Quijote, quien busca que los tiempos caballerescos resurjan, después de haber consumido gran cantidad de libros:

Es, pues, de saber que este sobredicho hidalgo, los ratos estaba ocioso, que eran los más del año, se daba leer libros de caballerías, con tanta afición y gusto, que olvidó casi todo punto del ejercicio de la caza y aun la administración de su hacienda. (Cervantes, 2005, p. 31).

Ambos, cuando tienen la oportunidad, salen para distorsionar su realidad circundante. Anteriormente se habló de que la realidad del caballero de la Mancha es más fácilmente rechazable, debido a que la sociedad con la que interactúa ve como mera locura a un hidalgo que aún cree en gigantes o hechiceros. En cambio, la de Emma es más factible, ya que su mundo de amantes es una realidad que no comparte sólo ella: las relaciones fuera del matrimonio se mantienen vigente en cualquier época de la humanidad. Aunque su manera de actuar está potenciada por las ficciones novelescas. Esto logra que su actitud con las personas que deciden entrar en su juego sea exacerbada, casi desesperada o loca. Como ocurre en el momento en el que Rodolfo, el primer amante, decide romper sus relaciones extramaritales con Emma: “¿Ha pensado usted bien su decisión? ¿Sabe a qué abismo la arrastraría, pobre ángel? No, ¿verdad? Usted iba, confiada y loca, creyendo en la felicidad, en el porvenir... iAh!, idesdichados de nosotros! ilnsensatos!" (Flaubert, 1981, p. 164). A diferencia de Sancho, como en el episodio de los molinos de viento, Rodolfo decide renunciar a la realidad idealizada de Emma. Otra diferencia de la protagonista de la obra de Flaubert con el de Cervantes es la posibilidad de reformarla a su conveniencia. Don Quijote, si él lo desea, puede justificar sus fracasos culpando a un enemigo que está tras sus pasos. Con Emma esto es imposible, ya que la realidad propuesta por el caballero andante, en su mayoría, está basado en 
la fantasía, donde existe la magia y pueden desaparecer o transformar objetos de acuerdo con su voluntad. Lo que pasa con Madama Bovary es que su

Ideal plenamente identificado, a partir de aquí, con las voluptuosidades tangibles de esa vida indolente y desocupada, de ese espejismo brillante que confunde con la verdadera vida y que le impedirá aceptar la realidad tal y como es. Una vez más Emma se deja engañar por lo que no es sino ilusión. (Martínez, 2007, p. 69).

A su manera, Emma, como personaje, muestra una enorme coherencia. Con sus absurdos, alcanza el sentido; las situaciones conflictivas en las que se encuentra la hacen caer en un estado de desesperación absoluta. Sus acciones, a pesar de considerarse como absurdas, no pueden desarrollarse de otra manera, debido al estado tan alterado por el que atraviesa. El personaje sufre varios cambios, aunque mantiene la misma línea de mujer que busca una idealización propia de la realidad. Se mantiene fiel desde su presentación en la novela, hasta el momento de su muerte. Se puede decir, entonces, que

quien nace torcido seguirá así toda su vida y será torcido lo que haga, y la educación no logrará cambiarlo; en este caso, las conductas de los personajes nada tendrán que ver con valores éticos o pedagógicos: se sitúan por encima del bien y del mal, y siguen una trayectoria independiente de cualquier esquema ético, con dependencia única de la voluntad del personaje. (Boves, 2018, p. 14).

Y Emma entra en esta definición, dado que su rol en la novela es la de encarnar a la femme fatale, de representar a la fatalidad por donde quiera que vaya, aun cuando las decisiones que toma la llevan únicamente a su autodestrucción, las cuales afectan a su esposo y, al final, incluso, indirectamente, a su hija. 
Entre la obra de Cervantes y Flaubert, vemos dos mundos caóticos que reposan en aparente calma. El choque de realidades es lo que los está alterando. La Francia de Emma ${ }^{4}$ va perdiendo su sentido conforme la protagonista interviene, y esto "permite una lectura realista, pero que integra en ese mundo verosímil elementos incongruentes, incoherentes, desde una lógica realista y racional" (Martínez, 2007, p. 78). Esta aparente falta congruencia se integra con los deseos de Emma, de su sentir con lo que la rodea. Es decir, le exige al mundo que le dé lo que le falta, lo que ella necesita para alcanzar su felicidad. A diferencia del Quijote, quien tiene una fortaleza inusitada para que la realidad se doblegue ante él, en un continuo tira y afloja. O como explica Deleuze (1969, p.57) "el sinsentido es lo que se opone al sentido en una relación simple con él; hasta el punto de que el absurdo se define siempre por un defecto del sentido, una carencia". Y esto se refleja tanto en Emma como en el Quijote, ya que una busca traer a su existencia un drama novelesco similar a lo que ella ha idealizado; y el otro quiere que los caballeros andantes revivan para que regrese la Edad de Oro, una época en la que antes se estaba mejor.

Tanto Emma, como don Quijote son personaje que han superado la prueba del tiempo. Su función, como protagonista, y la de Flaubert como escritor, es la de clarificar lo abstracto, como menciona Ortega y Gasset:

Esto sería oportuno; el novelista consume su tarea cuando ha logrado presentarnos en concreto lo que en abstracto conocíamos ya. Al cerrar el libro decimos: 'Así son, en efecto, las provincias adúlteras. Y estos comicios agrícolas son, en verdad unos comicios agrícolas'. Con tal resultado hemos satisfecho al novelista. (2012, p.63)

El personaje, al igual que la obra, tiene como crítico definitivo al tiempo. Al igual que se dice si una novela envejeció bien o no, se piensa que también se puede aplicar aisladamente con los

\footnotetext{
${ }^{4}$ Respecto al tiempo de Madame Bovary es posible notar un gran manejo de éste en la novela de Flaubert. Sabe en qué momento adelantar los acontecimientos, pausar o detenerse en el momento más preciso, todo bajo la perspectiva de Emma Bovary, quien "prisionera de su pequeña vida provinciana, alberga el sentimiento de que los días y los meses se acumulan unos sobre otros como los varios pisos del gorro de Charles o del pastel de bodas: un tiempo cíclico ritmado por el tintineo de la campana rajada o por el paso de las estaciones y del que ella sólo podrá evadirse con el suicidio" (Borneuf \& Ouellet, 1989, p. 156)
} 
personajes, ya sea porque sus acciones resultan anticuadas o simplemente porque ha cambiado la época. Con esto, se intenta decir que los actantes de las obras literarias responden a las necesidades de la sociedad. Lo que mencionaba Ortega y Gasset (2012, p.64) sobre presentar en concreto lo abstracto. Los gustos cambian o, en otras palabras, "queremos la ilusión de la apariencia, pero otras edades han tenido otras predilecciones. Presumir que la especie humana ha querido y querrá siempre lo mismo que nosotros, sería una vanidad".

\section{La locura quijotesca en el mundo de los banqueros}

Por otro lado, la literatura de Kafka se caracteriza por un estilo muy definido que, de la misma manera que Cervantes, ha sido replicado hasta el cansancio por autores que lo precedieron. Podría decirse que El proceso es su novela más quijotesca por lo pintoresco de sus personajes secundarios. Antes de entrar a fondo la novela, se considera necesario establecer una conexión entre Kafka y Cervantes. El escritor checo conocía la existencia del creador del Quijote, lo había leído y no sería extraño suponer que influyó en la producción de su literatura. Muestra de ello es su texto "La verdad sobre Sancho Panza" en un juego claramente quijotesco

Sancho Panza, quien, por lo demás, nunca se ha gloriado de ello, consiguió después de muchos años, en las horas nocturnas, mediante la lectura de una gran cantidad de novelas de caballerías y de bandidos, apartar de sí da tal modo a su demonio, al que posteriormente bautizó con el nombre de Don Quijote, que éste se dedicó a realizar las acciones más locas y absurdas, las cuales, al carecer de un objetivo predeterminado, pues éste tendría que haber sido Sancho Panza, no causaron daño a nadie. Sancho Panza, un hombre libre, siguió indiferente, tal vez sólo por cierto sentimiento de responsabilidad, a Don Quijote en sus aventuras y sobre ellos sostuvo una gran y útil conversación hasta su final (Kafka, 2003, p. 435).

La parodia está presente tanto en las historias de Quijote y Sancho. Su escritura es un juego de tergiversación de las novelas de caballería. Kafka, en este relato, no sólo muestra haber leído la obra de Cervantes, sino que entra voluntariamente a la realidad de caballeros, propuesta por el 
hidalgo de la Mancha. Sobre todo, se toma la libertad de contribuir en el laberinto de espejos del Quijote. La metaficción fue uno de los juegos de Cervantes y se hace presente en el momento que el narrador extradiegético de la novela dice haber encontrado los manuscritos de las aventuras del caballero, supuestamente escritos por un árabe llamado Cide Hamete Benengeli: "Con esta imaginación, le di prisa que leyese el principio y, haciéndolo ansí, volviendo de improviso el arábigo en castellano, dijo que decía: Historia de don Quijote de la Mancha, escrita por Cide Hamete Benengeli, historiador arábigo" (Cervantes, 2005, p. 74).

Kafka refleja este espíritu de la locura quijotesca en su novela sin terminar El proceso. El protagonista es Joseph K. un banquero ${ }^{5}$ que, de la nada, es detenido por una razón que él desconoce. Los captores lo vigilan en su pensión para informarle del inicio de su proceso; sin embargo, a pesar de lo que en un inicio piensa Joseph, su detención no le impide que realice sus actividades diarias:

— ¿Cómo puedo yo ir al banco, si estoy detenido?

- iVaya! - exclamó el inspector, que se encontraba ya cerca de la puerta de salida-. Usted no me ha comprendido bien, Está detenido, por supuesto, pero no impide que atienda sus quehaceres. Nadie le impedirá que lleve su vida normal (Kafka, 1985, p. 73).

Se considera que en este momento hay una semejanza con la novela cervantina, ya que, a partir de ese momento, se establecerá el curso de los siguientes capítulos en la obra. Además, Joseph K. estará obligado a emprender una desventura, yendo de un lado a otro, conociendo a personajes que sólo dificultarán más el intricado proceso al que lo han sometido. En este pasaje, es preciso volver al tema de lo absurdo presente también tanto en Madame Bovary como en El ingenioso hidalgo don Quijote de la Mancha, ya que Joseph K., al enterarse de su detención, se encuentra

\footnotetext{
${ }^{5}$ Kafka, gran parte de su vida, se mantuvo trabajando como burócrata. Los personajes de sus obras narrativas más importantes están inmiscuidos en el mundo oficinesco, en una época donde el mundo laboral comienza a ser cada vez más asfixiante. Kafka parecía sentirse asfixiado por su trabajo, pero disfrutaba escribir sobre ello. Desde siempre. "Entre el escritor y la cultura predominante existe una relación desigual y contradictoria: así, mientras que la novela refleja el individualismo burgués y la ideología del liberalismo, su afirmación de la libertad del hombre ocurre en un mundo ficticio que parece negarle" (Swingewood, 1988, p. 73).
} 
confundido al no saber por qué está siendo enjuiciado y esto "presenta un conflicto a los sentidos y para comprender la esencia del absurdo es necesario conocer lo que posibilita nuestras experiencias" (Pérez, 2016, p. 868).

Lo que hace peculiar el caso de Joseph K. es que, a diferencia del Quijote, la locura no va de dentro hacia fuera, sino que va de fuera hacia dentro. Con esto se intenta explicar que el espíritu quijotesco no se encuentra en el protagonista, sino que son los actantes secundarios con los que interactúa, quienes provocan el choque de realidades. Quienes encarnan el carnavalesco sistema de justicia que tiene en manos el destino de Joseph K. también son representantes de lo absurdo, como se puede ver en el siguiente pasaje:

-iAh! -exclamó K., levantando los brazos hacia lo alto, como si este repentino descubrimiento requiriera más espacio para explayarse-. Por lo que veo, todos ustedes son funcionarios de la justicia, pertenecen a esa cuadrilla de vendidos a la cual me refería y se han reunido aquí para escuchar y espiarme. Han simulado que pertenecían a partidos distintos para engañarme (Kafka, 1985, p. 110-111).

El lugar donde lo citan para su interrogatorio incluso puede considerársele quijotesco, ya que es un edificio cualquiera en el que se llevan a cabo los juicios, se tienen registros inconmensurables de todos los casos, además de que incluso abogados tienen sus oficinas en la misma construcción. Es una torre de babel de leyes en la que vive una pequeña parte del sistema de justicia. Este sitio, además de representar una contradicción, prueba que

[...] las proposiciones que designan objetos contradictorios tienen también un sentido. Sin embargo, su designación no puede efectuarse en ningún caso; y no tienen ninguna significación, que definiera el género de posibilidad de una tal efectuación. No tienen significación, es decir, son absurdas. (Deleuze, 1969, p. 31).

Estos objetos imposibles son representaciones de lo absurdo, los cuales Deleuze también denomina como el "extra-ser". 
Los lugares tienen una importancia especial en El proceso, ya que es en los distintos recintos que aparecen en la novela, donde se confronta lo absurdo con lo lógico. Es donde habitan seres que potencian lo inverosímil. Joseph K. representa lo racional, tiene una mente recta, formada por su trabajo en el banco. Su pensamiento parece desmoronarse en el momento que lo detienen por un mero capricho desconocido. Además de que es puesto a prueba conforme intenta averiguar una manera de liberarse de su proceso. Para lograrlo, está forzado a enfrentarse a personajes que sólo terminan por complicar su caso aún más. Por lo tanto, como menciona Deleuze:

Si distinguimos dos clases de seres, el ser de lo real como materia de las designaciones, y el ser de lo posible como forma de las significaciones, debemos añadir todavía este extra-ser que define un mínimo común a lo real y a lo posible y a lo imposible. (1969, p. 31).

Se necesita un espacio, en el que puedan convivir dos términos contrapuestos. Asimismo, estos lugares tienen la facilidad de aumentar con la profundidad de la narración para darle lógica a su sinsentido. Se piensa que para lograr esto, ambos autores, tanto Kafka, como Cervantes, recurrieron al uso de integrar otra historia, dentro de la trama principal, como una forma de continuar el juego de la metaficción ${ }^{6}$. Por ejemplo, en el Quijote también es posible encontrar estos "extra-seres", salvo que están deformados a conveniencia de los caprichos del caballero andante, como en la posada donde comienza a relatarse la novela de "El curioso impertinente": "Sacólos el huésped, y, dándoselos a leer, vio hasta obra de ocho pliegues escritos de mano, y al principio tenían un título tan grande que decía: Novela del curioso impertinente" (Cervantes, 2005, p. 265). Y, en Kafka, en el penúltimo capítulo, con la catedral que Joseph K. visita y conoce al sacerdote, quien intenta iluminar un poco la situación absurda por la que atraviesa, contándole la historia que ha sido nombrada como "Ante la ley":

\footnotetext{
${ }^{6}$ Este mismo juego podría parecer un desorden temporal completamente despótico. Los autores de estas novelas, al igual que muchos otros, muestran una gran maestría en la distorsión del tiempo. Se puede afirmar entonces que “Enfocada desde esta óptica, la inextricable red temporal de la novela no resulta ni tan gratuita ni tan arbitraria como les parece a muchos lectores, sino que corrobora la complejidad de un espíritu particularmente lúcido, vivaz e ingenioso" (Borneuf \& Ouellet, 1989, p. 162).
} 
-Eres una excepción entre todas las gentes de la justicia-. Tengo más confianza en ti que en cualquiera otro de ellos, y conozco ya a muchos. Contigo puedo hablar abiertamente.

-No te engañes-dijo el cura.

-¿¿n qué podría engañarme? - preguntó $\mathrm{K}$.

-Te engañas acerca de la justicia-le dijo el sacerdote-, y de este error se dice en los escritos que prolongan la ley (Kafka, 1985, p. 258).

\section{Conclusión}

La novela de Cervantes indudablemente fue un parteaguas para la literatura. Tanto que ha sido una influencia importante para el desarrollo de la literatura contemporánea. Sin embargo, esto no podría haber sido posible sin buenos escritores que hayan entendido la obra a plenitud, tal como lo hicieron Franz Kafka y Gustave Flaubert. Emma Bovary es un personaje que tuvo la función de hurgar en los aspectos de la infidelidad en las provincias agrícolas, sin dejar de lado la referencia intertextual que remite a Cervantes. En cambio, a Kafka también podría considerársele, como un aprendiz del Quijote, quien aprendió y se apropió de las técnicas que pudo identificar de la primera novela moderna. Si tomamos en cuenta, como punto de partida el trabajo de Cervantes, e incluso si se busca aún más atrás, es posible percatarse que la literatura se refiere a ella misma, al igual que los mismos personajes pueden estar construidos con rasgos de otros que los antecedieron. Es obvio que la novelas muestran una evolución con el paso de los siglos y responden, a través de sus personajes, a las necesidades causadas por los problemas de una determinada época. Sin embargo, sólo aquellos que sean atemporales, como Emma Bovary y Joseph K., serán capaces de alcanzar la trascendencia.

\section{Referencias}

Borneuf, R. \& Ouellet R. (1989). La novela. España: Ariel.

Boves, M. (2018). El personaje literario en el relato. España: Consejo Superior de Investigaciones Científicas. 
Cervantes, M. (2005). El ingenioso hidalgo don Quijote de la Mancha. México: Tomo.

Deleuze, G. (1969). Lógica del sentido. Colombia: ARCIS.

Flaubert, G. (1981). Madame Bovary. México: Porrúa.

Kafka, F. (2003). Cuentos completos. España: Valdemar.

Kafka, F. (1985). El proceso. México: Porrúa.

Madrigal, L. (2018). Cervantes visto por los clásicos. Revista de estudios cervantinos, I, pp. 57-60.

Martínez, P. (2007). La huella de Cervantes en la obra de Flaubert. Dossier, 37, pp. 61-80.

Ortega y Gasset, J. (2012). Meditaciones sobre el Quijote. España: Gredos.

Pérez, J. (2016). Las formas del absurdo y el sinsentido en la literatura. Signa, 25, pp. 865-877.

Swingewood, A. (1988). Novela y revolución. México: Fondo de Cultura Económica. 